\title{
Promoting gender equity as a strategy to reduce HIV risk and gender-based violence among young men in India
}

\author{
Ravi K. Verma \\ Population Council \\ Julie Pulerwitz \\ Vaishali Sharma Mahendra \\ Population Council \\ Sujata Khandekar \\ A.K. Singh \\ Population Council
}

See next page for additional authors

Follow this and additional works at: https://knowledgecommons.popcouncil.org/departments_sbsr-hiv

Part of the Demography, Population, and Ecology Commons, Domestic and Intimate Partner Violence Commons, Health Policy Commons, International Public Health Commons, Medicine and Health Commons, and the Public Health Education and Promotion Commons How does access to this work benefit you? Let us know!

\section{Recommended Citation}

Verma, Ravi K., Julie Pulerwitz, Vaishali Sharma Mahendra, Sujata Khandekar, A.K. Singh, S.S. Das, Sunil Mehra, Anita Nura, and Gary Barker. 2008. "Promoting gender equity as a strategy to reduce HIV risk and gender-based violence among young men in India," Horizons Final Report. Washington, DC: Population Council. 


\section{Authors}

Ravi K. Verma, Julie Pulerwitz, Vaishali Sharma Mahendra, Sujata Khandekar, A.K. Singh, S.S. Das, Sunil Mehra, Anita Nura, and Gary Barker 


\section{Promoting Gender Equity as a Strategy to Reduce HIV Risk and Gender-based Violence Among Young Men in India}
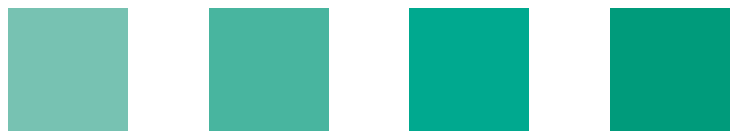

Horizons Program

CORO

MAMTA

DAUD

Instituto Promundo 


\title{
Promoting Gender Equity as a Strategy to Reduce HIV Risk and Gender-based Violence Among Young Men in India
}

\author{
Affiliations at the time of the study \\ Ravi Verma (Horizons/Population Council) \\ Julie Pulerwitz (Horizons/PATH) \\ Vaishali Sharma Mahendra (Horizons/Population Council) \\ Sujata Khandekar (CORO) \\ A K Singh (Population Council) \\ S S Das (MAMTA) \\ Sunil Mehra (MAMTA) \\ Anita Nura (DAUD) \\ Gary Barker (Instituto Promundo)
}

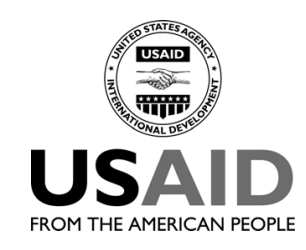

\section{Hgrizons}
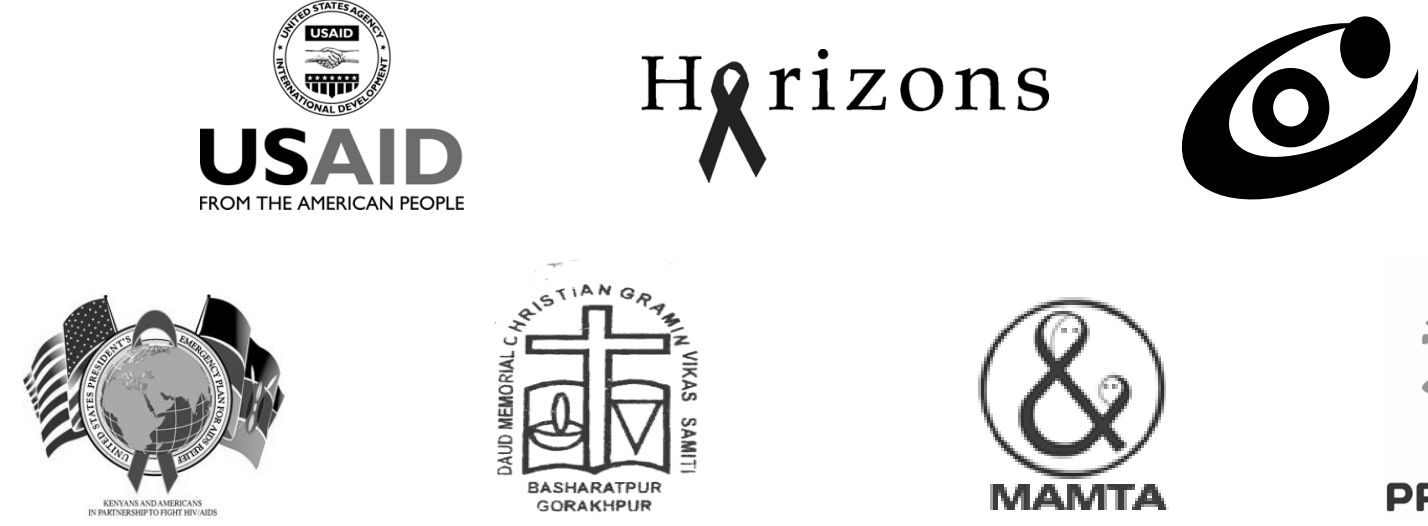

MAMTA

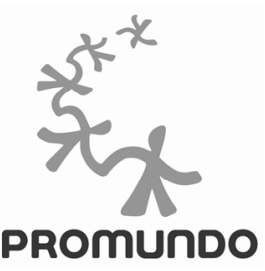




\section{Acknowledgments}

Several people and various organizations have contributed to this study. While it may not be possible to include all here, we would like to mention a few. They include Mahendra Rokade, Vilas Sarmalkar, and the team from CORO for Literacy, Mumbai; Vijay Kumar from Daud Gorakhpur; Marcos Nascimento, Christine Ricardo, and Marcio Segundo, from Instituto Promundo; Valeria Rocha at World Education; Asha Bhende, Hemant Apte, and Prakash Fulpagare, Independent Consultants; V. L. Thomas and Anil Paul from Population Council, New Delhi; and LeeAnn Jones and Ellen Weiss from the Horizons Program. We would also like to thank colleagues from the International Institute for Population Sciences (IIPS) who participated in various initial brain-storming meetings in Mumbai, Imtiaz Khan from MAMTA for monitoring program implementation in Gorakhpur, and Synovate for conducting the baseline and endline surveys in Mumbai and Gorakhpur. In addition, we gratefully acknowledge the MacArthur Foundation and SSL International for supporting the study at various stages.

USAID

This study and final report were made possible by the President's Emergency Plan for AIDS Relief and the generous support of the American people through the United States Agency for International Development (USAID) under the terms of Cooperative Agreement No. HRN-A-00-97-00012-00. The contents are the responsibility of the Horizons Program and do not necessarily reflect the views of USAID or the United States Government.

Published in July 2008.

\section{(P) Population Council \\ The Population Council is an international, non-profit, nongovernmental institution that seeks to improve the well-being and reproductive health of current and future generations around the world and to help achieve a humane, equitable, and sustainable balance between people and resources. The Council conducts biomedical, social science, and public health research and helps build research capacities in developing countries. Established in 1952, the Council is governed by an international board of trustees. Its New York headquarters supports a global network of regional and country offices.}

Copyright (C) 2008. The Population Council Inc.

Suggested citation: Verma, Ravi, Julie Pulerwitz, Vaishali Sharma Mahendra, Sujata Khandekar, A K Singh, S S Das, Sunil Mehra, Anita Nura, Gary Barker. 2008. "Promoting gender equity as a strategy to reduce HIV risk and gender-based violence among young men in India," Horizons Final Report. Washington, DC: Population Council.

This document may be reproduced in whole or in part without permission of the Population Council provided full source citation is given and the reproduction is not for commercial purposes. 


\section{Table of Contents}

$\begin{array}{ll}\text { Executive Summary } & 1\end{array}$

$\begin{array}{lr}\text { Introduction } & 5\end{array}$

Why gender matters $\quad 5$

$\begin{array}{ll}\text { Study objectives } & 6\end{array}$

Study locations: Mumbai and Gorakhpur $\quad 8$

Study design and sample sizes $\quad 8$

Data collection and outcome measures $\quad 9$

$\begin{array}{ll}\text { Data analysis } & 12\end{array}$

$\begin{array}{ll}\text { Characteristics of the study population } & 12\end{array}$

$\begin{array}{ll}\text { The Yaari-Dosti Intervention } & 13\end{array}$

Promoting gender-equitable norms and behaviors $\quad 13$

$\begin{array}{ll}\text { Peer-led group educational sessions } & 13\end{array}$

$\begin{array}{ll}\text { Lifestyle social marketing campaign } & 14\end{array}$

$\begin{array}{lr}\text { Results } & 16\end{array}$

Baseline results $\quad 16$

$\begin{array}{ll}\text { Post-intervention results } & 18\end{array}$

$\begin{array}{ll}\text { References } & 31\end{array}$ 



\section{Executive Summary}

In India, young people aged 15-24 years accounted for 37 percent of people living with HIV (IIPS and Macro International 2007). Although there is increasing awareness of the role that gender norms play in fostering partner violence and HIV risk for young men and their sexual partners, few interventions have attempted to influence these norms as a key strategy for HIV and violence prevention. In addition, few evaluation studies have attempted to measure the impact of prevention interventions that focus on genderrelated issues, including changes in support for inequitable gender norms. In response to this gap, the Horizons Program, CORO for Literacy, MAMTA, and Instituto Promundo developed, piloted, and scaled-up a behavior-change intervention, Yaari-Dosti. The interventions were based on a successful program that addressed gender norms in Brazil. The team conducted operations research to examine the effectiveness of the interventions to improve young men's attitudes toward gender roles and sexual relationships, and to reduce HIV risk behaviors and partner violence. Support for the various phases of this project was provided by the MacArthur Foundation, USAID, SSL International, and the European Union.

\section{Methods and Intervention}

Set in urban slums of Mumbai in the state of Maharashtra and in rural villages in Gorakhpur (Uttar Pradesh), the study used a quasi-experimental design to test the impact of different combinations of intervention activities on young men's support for inequitable gender norms, HIV/STI risk behaviors, and partner violence. The sample included married and unmarried young men aged 16-29 years in urban settings and aged 15-24 years in rural settings.

In Mumbai, the study used a three-arm design. Participants in Arm 1 received group education sessions and a lifestyle social marketing campaign (GES + LSSM); those in Arm 2 received only group education sessions (GES). Arm 3 was the comparison site and received a delayed intervention. In each of these three sites, surveys were administered before any intervention activity $(\mathrm{n}=886)$ and after the intervention had been ongoing for six months $(\mathrm{n}=537)$. In the rural areas of Gorakhpur, young men in one block of villages were exposed to group education sessions only (GES), and in the other block of villages they were exposed to an unrelated intervention. A survey was administered to the participants prior to the intervention in the intervention arm and in the comparison site $(\mathrm{n}=1,040)$ and six months later $(\mathrm{n}=601)$. In this report, matched cohort data from young men who were interviewed both during baseline and follow up are presented.

Attitudes toward gender norms of the young men were assessed using a version of the Gender Equitable Men (GEM) Scale developed initially in Brazil and adapted to the Indian context. A change in GEM Scale scores, as well as in a number of behavioral indicators including condom use, violence against partners, and communication with partners, were evaluated. Further, associations between the GEM Scale and behavioral indicators were determined at baseline and follow up, and across the intervention arms. 


\section{Hgrizons}

\section{Key Findings}

\section{At baseline, the majority of young men supported inequitable gender norms.}

GEM Scale scores were trichotomized into "high equity," "moderate equity," and "low equity." At baseline, less than 10 percent of the young men in all the sites were categorized as "highly equitable." The majority of young men were distributed across "moderate" and "low" equity categories. There was not much difference between the rural and urban sites.

\section{Young men reported substantial HIV/STI risk practices at baseline.}

Reports of at least one STI symptom or other factor indicative of poor sexual health in the three months prior to the survey was substantial in all groups, but highest in the rural sites. Less than 10 percent of the young men had ever taken an HIV test. More than one-third of young men in both urban and rural sites reported they had been physically or sexually violent against a partner in the three months prior to the survey. Across the urban sites, 44 percent of respondents were sexually experienced, with an average age of 18 years at sexual initiation. Young men from the rural area were somewhat more likely to be sexually experienced; 50 percent reported having had sex with any type of partner, and their mean age of sexual initiation was 16.

At least one-fourth of young men in the rural and urban sites who reported having sex in the last three months had reported having sex with two or more partners. Condom use at last sex with all partner types in the last three months varied from one-fourth to a little less than half, depending on the study site.

\section{Support for inequitable gender norms was associated with HIV risk.}

At baseline, lower scores on the GEM Scale were associated with more reported HIV risk behaviors. Combined data from the three urban sites indicate that young men reporting more support for inequitable norms were significantly $(\mathrm{p}<.05)$ less likely to use condoms and more likely to report symptoms of poor sexual health. In rural sites, there was a significant association $(p<.05)$ between lower GEM Scale scores and reporting at least one symptom of poor sexual health, partner violence, and sex with more than one partner.

\section{Intervention participants reported less support for inequitable gender norms after the intervention.}

There was a significant $(\mathrm{p}<.05)$ positive shift of young men moving from the "low gender equity" category into the "moderate gender equity" and "high gender equity" categories in the intervention sites. Changes in the comparison sites were not significant. Logistic regression analysis at follow up found that a positive change in gender attitudes was correlated with exposure to the intervention. 


\section{Partner communication significantly improved in the intervention sites.}

In both urban intervention sites the number of men discussing condoms, sex, STIs, and/or HIV with a partner increased almost one and a half times from baseline to follow up, while it decreased in the comparison site. The proportion of men communicating about any of these topics with a partner more than doubled in the rural intervention arm. However, it also more than doubled in the comparison arm.

\section{There was a significant increase in condom use at last sex with all partner types in the intervention areas.}

Among the young men who had sex in the last three months, condom use at last sex with all sexual partners increased significantly $(\mathrm{p}<0.05)$ in the urban and rural intervention sites from baseline to follow up. In contrast, condom use stayed the same or decreased slightly in the comparison sites. Logistic regression analysis at follow up showed that men in the intervention arms were 1.9 times more likely to have used condoms at last sex with all partners in Mumbai $(\mathrm{p}<0.001)$ and 2.8 times more likely to have used them in Gorakhpur $(\mathrm{p}<0.001)$ than those in the comparison arms in each setting.

\section{Self-reported violence against a partner declined in the intervention sites.}

The proportion of men in the urban and rural intervention sites who reported violence against a partner (either sexual or non-sexual/romantic) in the last three months declined significantly $(\mathrm{p}<0.05)$. In contrast, reported partner violence increased significantly in both the urban and rural comparison groups.

\section{There was a positive trend toward improvements in GEM Scale scores being associated with decreases in HIV/STI risk behaviors.}

Analysis was conducted to determine if there was a correlation between positive changes in attitudes among respondents (calculated by subtracting the GEM Scale score at follow up from the baseline GEM Scale score) and reductions in HIV risk behaviors. Although these correlations were not statistically significant, there was change in the right direction.

\section{Young men in the intervention sites reported more positive attitudes toward PLHIV.}

Young men in the intervention arms showed significant improvements in their attitudes toward people living with HIV (PLHIV), while attitudes significantly worsened among the comparison groups in both Mumbai and in Gorakhpur.

\section{Young men participated actively in the group education sessions.}

Approximately seven in 10 intervention participants attended at least half of the sessions (at least 11 out of 23 total sessions). Some of the most well-attended sessions, with over 70 percent attendance in all three sites, were: "STI and HIV," "Me and my body," "Power and violence," "Testing and counseling," "I am HIV-positive," "Condom use," "What is Gender," and "Sexuality and Reproduction." 


\section{Hgrizons}

\section{Discussion and Conclusions}

The results of this study suggest that young men became less supportive of inequitable gender norms after participating in the interventions, whereas in the comparison groups, there tended to be little or no positive change, or the changes were in the wrong direction. Similarly, there were significant improvements among intervention participants in key outcome indicators, including condom use, partner communication, partner violence, and attitudes toward PLHIV. The study also found that the impact of the group education intervention alone was comparable with the impact of the combined intervention that included the lifestyle social marketing campaign. The intervention activities were also considered culturally appropriate for both rural and urban different settings in India, based on qualitative findings. Given this study's successful results, project collaborators are now proceeding to scale up the Yaari-Dosti program in India's public education sector.

This study showed that change in attitudes and behaviors is a complex and gradual process. Qualitative observation of those who attended the sessions suggests that changes among the young men happened in stages. In the initial stages of the intervention, young men who came into the sessions often denied the idea of gender-based inequality in their society and in their individual actions. As they progressed through the sessions, they moved their position toward accepting that gender-based inequality does exist. Further into the intervention, they acknowledged that some of their attitudes and behaviors were gender inequitable, and that it would be beneficial to change these views.

To maximize the chances of long-term sustainability of these positive changes, there is a need to regularly reinforce the messages related to alternative forms of masculinity and to further facilitate a supportive environment for these changes. It will be important to build alliances for large scale and ongoing discourse on men and masculinities. An immediate response that is recommended is explicit inclusion of discussions of manhood and masculinities in educational activities and widespread promotion of critical reflection about violence and manhood.

There are limitations of this study that should be noted. First, there is a possibility that due to the selfselection of participants who joined the study, they may be more likely to change than those who did not join. Second, outcomes measures relied on self-reports from participants. It is possible that men participating in the interventions were more likely to give what they felt were the "correct" or "desirable" answers. Examples of ways to strengthen findings in future studies include use of a research design with group randomization, use of more objective outcome measures such as biological markers for STI infection rather than self-report of symptoms, and inclusion of interviews with partners of participants to assess their reports of violence reduction and adoption of safer sex practices. 


\section{Introduction}

In 2006, there were an estimated 2.5 million people living with HIV in India (NACO 2007). Young people ages 15-24 years accounted for 37 percent of the HIV-infected population (IIPS and Macro International 2007). This underscores the need to develop effective, youth-oriented HIV prevention programs for this age group.

In many parts of the world, inequitable gender roles are promoted as the norm during the socialization process for both males and females (Barker 2000a; UNAIDS 1999). Growing evidence suggests that the resulting gender inequity in relationships, where males have greater power than females, often leads to risky sexual behaviors as well as sexual coercion and physical violence, circumstances under which HIVprotective behaviors are difficult to initiate and maintain. Therefore, addressing gender norms, defined as the societal messages that dictate what is appropriate or expected behavior for males and females, is increasingly recognized as a key strategy to prevent the spread of HIV infection, particularly among young people (Weiss, Whelan and Gupta 2000; Barker 2000b).

Although there is increasing awareness that norms encouraging gender inequality play a role in fostering HIV risk behaviors and partner violence, promoting social norms in favor of greater gender equity is challenging. Few interventions have attempted to directly influence these norms, and few evaluation studies have attempted to measure changes in support for them. In response to this gap, and in light of positive findings from an intervention designed to address gender norms in Brazil (Pulerwitz et al. 2006), the Horizons Program; CORO for Literacy, an India-based NGO; and Instituto PROMUNDO, a Brazilian $\mathrm{NGO}$, conducted operations research in India to examine the impact on young men of promoting gender equity as part of an HIV prevention program.

\section{Why Gender Matters}

As males and females grow up, they are exposed to and internalize societal messages about appropriate behaviors for men versus women. Often these gender norms encourage roles and behaviors that are inequitable and harmful, which can place men and their sexual partners at risk of various negative health outcomes, including HIV and other sexually transmitted infections (STIs) (Rivers and Aggleton 1999). As part of this socialization process, styles of interaction in intimate relationships are often "rehearsed" during adolescence, and continue into adult relationships (Archer 1984; Erikson 1968; Barker 2000a and 2000b).

Young men in South Asia, including India, mature and develop in a male-dominated context, with little contact in the post-pubertal period with female peers and little or no sex education. Under these circumstances, masculinity often becomes characterized by male sexual dominance, unequal gender attitudes and behaviors, frequent use of harassment or teasing of young women by men, and lack of sexual knowledge (Pelto, Joshi, and Verma Joshi 1999; Verma and Mahendra 2004; Greene 1997).

It has also been shown that gender role differentials widen during adolescence (Devasia 1991; Bruce, Lloyd, and Leonard 1995) as boys enjoy privileges reserved for men such as autonomy, mobility, opportunity, and power, while girls endure restrictions as parents curtail their mobility, withdraw them from school, and closely monitor their interactions with males (Greene 1997). While gender norms afford 


\section{Hgrizons}

boys and young men many advantages compared to their female peers, including greater mobility, these same norms can foster vulnerabilities among males. Specifically, young men may feel pressure to prove their sexual prowess by having unprotected sexual relationships, may feel hindered from seeking information about sexual and reproductive health (SRH) and HIV issues, and face peer pressure to prove their dominance over girls (Barker 2000b). Differing social advantages have direct and indirect effects on reproductive behavior and future health and well-being, with specific and different implications for boys and girls (Mensch, Bruce, and Greene 1998). Negative consequences include gender-based violence, sexual abuse of women, and homophobia as expressions of masculinity (Verma et al. 2005).

Studies from various countries have found that young men often view sexual initiation as a way to demonstrate that they are "real" men; that is, to affirm their identity as men (Marsiglio 1988). Boys often feel that they must repeatedly prove their manhood through sexual activity. Another common belief about sexuality and sex among young men is that they "know it all," when in fact they are frequently uninformed or misinformed. Various studies suggest that young men have misperceptions about their own bodies, about HIV/STI transmission, and about female sexual anatomy and functioning (Morris 1993).

Social norms and attitudes that put men in a position of sexual dominance have dire consequences for women's ability to control their own reproductive and sexual health. Social norms frequently hold that it is the male's responsibility to acquire condoms, since for a young woman to carry condoms may be seen as "promiscuous" (Childhope 1997; Weiss, Whelan, and Gupta 2000). At the same time, the prevailing norms in many settings dictate that since reproductive and sexual health are "female" concerns, women must be the ones to suggest contraceptive use (Greene et al. 2004). Gender-based power dynamics exacerbate these issues, and women often cannot negotiate condom use when they wish to do so (Amaro 1995; Pulerwitz et al. 2002).

Another relevant example of men's behavior toward women related to inequitable norms is the use of violence against women. Recent World Health Organization (WHO) reports document that in 48 population-based surveys, between 10 and 69 percent of women reported being physically assaulted by an intimate male partner at some point in their lives (WHO 2005). A study in India found that use of violent behaviors was an integral component of describing a "real man" and manliness (Verma et al. 2005).

In addition to shaping sexuality, gender norms also socialize boys into a set of ideas about household roles and childrearing. Studies conducted in various countries find that fathers tend to contribute about one-third to one-fourth of the time that mothers do in direct child care (Population Council 2001). While there are substantial individual and context-specific differences, research suggests that young men identify less involvement in domestic roles as part of their understanding of masculinity.

This brief review of the literature confirms that gender norms related to sexual and reproductive health and risk, sexuality, domestic life, and violence influence the socialization of young men worldwide, including in India, and that these norms should be addressed in order to reduce HIV risk and promote gender equality among youth.

\section{Study Objectives}

The objective of this study was to reduce HIV vulnerability among men and women and to reduce young men's use of violence against women and girls through the promotion of gender equitable attitudes and behaviors. More specifically, the study aimed to: 
- Adapt the Gender Equitable Men (GEM) Scale, initially tested and developed in Brazil, to the Indian context for use as an evaluation tool.

- Test the impact of peer-led group educational activities and community-based social marketing campaigns in promoting gender equitable attitudes and behaviors and safe sexual practices among young men from low-income communities in Mumbai.

- Adapt and test the effectiveness of peer-based group educational activities among young men in rural settings in Gorakhpur, Uttar Pradesh. 


\section{Hgrizons}

\section{Methods and Study Population}

\section{Study Locations: Mumbai and Gorakhpur}

This quasi-experimental study was set in two sites: urban poor communities in Mumbai and rural poor communities in Gorakhpur.

Initially, the research team conducted formative research, and developed and piloted a behavior-change intervention (Yaari-Dosti) with young men in a low-income community of Mumbai (Verma et al. 2006). As a result of positive evaluation findings, the intervention was expanded in three similar low-income communities in Mumbai: Vashi Naka, Mankhurd, and Cheeta Camp. These are large slum communities located in the northeastern part of Mumbai, each with a population over 150,000. The intervention partner, CORO for Literacy, has had a long-standing presence in these areas working on community development issues related to women's empowerment, literacy, health and sanitation, and disaster management. These communities are culturally and religiously mixed. In some pockets of the study area, Muslims constitute approximately half of the population, with Hindus and Buddhists also represented in large numbers. A majority of the individuals in these communities are migrants, most often single males from other states in India. A majority of the migrants are from eastern districts of rural Uttar Pradesh, followed by those who have migrated from rural Maharashtra state and south Indian states. Migrants tend to live in congested localities with shared accommodation and maintain contact with their natal homes.

Because many of the men in the Mumbai study communities have strong links to Uttar Pradesh, the research team selected a rural area in that state (Gorakhpur in eastern Uttar Pradesh) to serve as the rural study site, for some comparability between groups thus this study examined the efficacy of the intervention in both urban and rural communities. In Gorakhpur, the intervention was implemented by MAMTA (an NGO located in New Delhi that works across the country on adolescent health issues with multiple partners) and DAUD, an NGO based in Gorakhpur.

\section{Study Design and Sample Sizes}

The study used a pre/post, quasi-experimental design with three arms in the urban site of Mumbai and two arms in the rural site of Gorakhpur. Study activities were first implemented in Mumbai followed by Gorakhpur.

In Mumbai, the community of Vashi Naka served as Arm 1. The intervention in this community consisted of group education sessions and a lifestyle social marketing campaign (GES + LSSM). Arm 2 was the community of Mankhurd where only the group education sessions were implemented (GES). Arm 3 in Cheetah Camp served as the comparison group and received a delayed GES intervention.

To recruit young men for the study in Mumbai, 10 peer leaders conducted various group formation activities in the selected communities designed to engage young men in the intervention. Each of the peer leaders formed two groups of about 15 young men each who after providing informed consent were enrolled in the study. In all, a total of 875 young men were enrolled in the three urban communities at the start of the intervention and all of them participated in the baseline survey. After the intervention, a total of 537 young men participated in the follow-up survey, a response rate of more than 50 percent in each of the three communities (see Table 1). 
In the rural site (Gorakhpur), the community of Pali received GES, and Bhathat served as the comparison site, receiving an unrelated intervention on community sanitation and hygiene. Based on power calculations indicating the necessary sample size, the research team aimed to follow 300 young men per arm. Assuming approximately 40 percent loss at follow up based on the urban experience, 500 men were recruited by peer leaders through various group formation activities to participate in the baseline survey and intervention in each arm. Post-intervention, there was almost no loss to follow up, so, to maximize the representativeness of the 300 person sample to be analyzed, the team used systematic random sampling to select 300 of these young men in each community to participate in the follow-up survey (see Table 1).

In this report, matched cohort data of young men who were interviewed both during baseline and follow up are presented. Table 1 summarizes the sample sizes at baseline and follow up.

Table 1 Sample sizes by study site

\begin{tabular}{lcccc}
\hline Community & & Intervention & $\begin{array}{c}\text { Baseline survey } \\
\mathbf{n}\end{array}$ & $\begin{array}{c}\text { Follow-up survey } \\
\text { n (retention) }\end{array}$ \\
\hline Mumbai & Vashi Naka & GES+LSSM & 333 & $197(60 \%)$ \\
& Mankhurd & GES & 321 & $175(54 \%)$ \\
& Cheetah Camp & Delayed intervention & 221 & $165(75 \%)$ \\
\hline Gorakhpur & Pali Block & GES & 524 & $300(\mathrm{NA})$ \\
& Bhathat Block & Unrelated intervention & 516 & $301(\mathrm{NA})$ \\
\hline
\end{tabular}

\section{Data Collection and Outcome Measures}

Synovate Social Research Group, an independent research agency, collected the quantitative data using handheld devices. The research team received intensive training on the use of handheld devices and its software (Perseus) in the classroom and in the field. Systems were developed to download the survey data from the handhelds to the mainframe computer on a daily basis to ensure that the data were not lost. In addition to the quantitative data, an independent team of researchers recruited by the partner organizations in Mumbai and Gorakhpur collected qualitative data through in-depth interviews with participants, and in some cases their partners, to aid in the interpretation of the attitudinal and behavioral survey data.

The research team worked very closely with the implementing partners to arrange the participant interviews. Participants were informed about the study objectives, study design, and the need for follow up interviews. Informed consent was obtained from each participant prior to participation.

The key indicators used to assess program impact were attitudes toward gender norms (measured by an Indian adaptation of the GEM Scale), perpetration of partner violence, sexual behavior, condom use, partner communication, attitudes toward people living with HIV (PLHIV), and self reports of symptoms suggestive of poor sexual health. 


\section{Hgrizons}

For sexual behavior, sexually experienced young men were asked about their age at sexual debut; sexual intercourse with different partners including wives, girlfriends, male partners, sex workers, and casual partners (male or female); different types of and number of sexual partners in the last three months; and types of sex acts (vaginal, anal, or oral sex) with each partner. The responses were combined to create a variable representative of participants having had sex with multiple partners in the last three months.

Sexually experienced respondents were also asked about protected sex. Specifically, they were asked about condom use during the last three months with each partner type and what kind of sex they had when a condom was used (vaginal and/or anal intercourse). If a respondent used a condom the last time they had vaginal and/or anal intercourse with all of their sex partner(s) in the last three months, it was coded as condom use at last intercourse with all partner types.

To assess sexual health problems, young men were asked whether they had experienced any of 13 symptoms ${ }^{*}$ during the previous six months. All positive (yes) responses were combined to create a variable representative of a participant having had at least one sexual health problem in the past six months.

Ten separate, dichotomous ("yes" or "no") questions were asked about partner violence. These questions included if the participant had done any of the following to any of their partners in the previous six months: punched, slapped, kicked, pushed, pulled the hair of, hit with an object, insulted, humiliated, threatened, or forced to have sex. Partners included wives, girlfriends (including those they had not had sex with), sex workers, casual sex partners, and male sex partners. A "yes" response to one or more of these questions was considered as having perpetrated partner violence in the past six months.

Partner communication was assessed by asking respondents if they had any discussions with their female partners (wives, girlfriends, casual partners, and/or sex workers) on any of the following topics: HIV, STIs, condom use, and sex.

A series of 20 statements was used to assess attitudes toward PLHIV. For each statement, a score of "1" was given to those who had a negative attitude toward PLHIV, "2" for undecided, and " 3 " for a positive attitude toward PLHIV. The combined score could range from a minimum of 20 to a maximum of 60 points. This attitudes index was found to be reliable at baseline for Mumbai respondents (Cronbach alpha .71) and Gorakhpur respondents (Cronbach alpha .79). If at follow up a person scored higher than his score at baseline, it was categorized as a positive change in attitudes; if a person scored lower or the same as baseline, it was considered as "no or negative change" in attitudes toward PLHIV.

\section{Indian adaptation of the Gender Equitable Man (GEM) Scale}

The GEM Scale was developed by the Horizons Program and Instituto Promundo with young men aged 15 to 24 years (Pulerwitz and Barker 2008). The original scale includes 17 attitudinal statements about inequitable gender roles (and seven statements about equitable gender roles) in areas of domestic work and child care, sexuality and sexual relationships, reproductive health and disease prevention, intimate partner violence, and attitudes toward homosexuality and close relationships with other men. Through

\footnotetext{
* These were wounds or cuts on your sexual organs; bumps and lumps under the skin in the genital region; burning, stinging, or difficulty when urinating; yellow or greenish discoloration of urine; blood in urine; puss with a strong odor; pain during sex; warts in the genital and/or anal region; redness and itchiness on the penis; small blisters on the tip of the penis; lack of erection; early ejaculation; weakness and itching around genitals.
} 
formative research and a review of the Indian literature on women's status, the GEM scale was adapted to the Indian context by adding specific items. For the Indian adaptation, 34 items, including the 24 original GEM Scale items, were tested using factor analysis and internal consistency checks (Cronbach alpha .78), from which 15 items were selected. Like the original, the items on the Indian adaptation of the GEM Scale are related to multiple domains: reproductive health and disease prevention, sexuality, violence, and domestic life and child care (see Table 2).

Each item on the GEM Scale has three response categories: agree, somewhat agree, and do not agree. Each item was scored such that one point was given for the least-equitable response, two points for the moderately-equitable response, and three points for the most-equitable response. Given this scoring system, a participant who gave the least equitable response to all items would receive a total score of 15 and a participant who gave the most equitable response to all items would receive a score of 45 . In order to make the results easier to interpret, respondents were categorized based on their total scores: low equity (15-25), moderate equity (26-35), and high equity (36-45).

In addition to categorizing the GEM Scale scores, changes in attitudes over time were also analyzed in order to correlate these changes with other outcomes. For this purpose, a new variable was created for each respondent that reflected his change in GEM Scores over time. If after the intervention an individual's score increased, it was coded as "positive change" and if it stayed the same or decreased, it was coded as "no or negative change."

\section{Table 2 India-adapted GEM Scale Items}

\section{Reproductive health and disease prevention}

It is a woman's responsibility to avoid getting pregnant

I would be outraged if my wife asked me to use a condom

A real man produces a male child (I)

\section{Sexuality}

Men need more sex than women do

You don't talk about sex, you just do it

Men are always ready to have sex

Men need other women even if the things with his wife are fine

A real man is one who can have sex with a woman for a long time (I)

\section{Violence}

It is okay for a man to hit his wife if she won't have sex with him

A woman should tolerate violence in order to keep her family together

There are times when a woman deserves to be beaten

\section{Domestic life and child care}

A man should have the final word about decisions in his home

Giving the kids a bath and feeding the kids are the mother's responsibility

A man is happily married only if his wife brings a big dowry (I)

A married woman should not need to ask her husband for permission to visit her parents/family (I)

Note: (I) Indicates India specific items 


\section{Hgrizons}

\section{Data Analysis}

Quantitative data were analyzed using SPSS 13.0 data analysis software. To determine changes in behaviors and attitudes of the study groups over time, chi-square tests were used as the statistical test of association. Comparison of mean GEM Scale scores before and after the intervention were analyzed using $\mathrm{t}$-tests. ANOVA test of variance was used to assess the significance of the variation in the mean GEM scores across the three groups in Mumbai and between the two groups in Gorakhpur. Logistic regression for correlated data was used to determine associations between changes in gender attitudes and changes in HIV risk, partner violence, and partner communication after controlling for age, education, marital status, and study arm.

Qualitative research data were transcribed into detailed notes by the researchers following the interview. These transcripts were then translated from regional languages into English and then typed into Microsoft Word. Key themes and codes were developed after an initial reading of all the interviews by multiple researchers.

\section{Characteristics of the Study Population}

Table 3 presents sociodemographic characteristics of the baseline samples in Mumbai and Gorakhpur. Participants in all the study arms were similar with respect to age and median years of education. Participants from rural Gorakhpur, on average, had sex two years earlier than those in Mumbai. Additionally, a larger proportion of participants from Gorakhpur were married than those in Mumbai. This reflects the tradition of early marriage in rural Uttar Pradesh. Employment varied greatly between the different groups. These differences in marital status and employment status were controlled for when undertaking analysis for assessing the impact of the intervention on changes in attitudes and risk behaviors.

Table 3 Baseline characteristics of study population

\begin{tabular}{|c|c|c|c|c|c|}
\hline & \multicolumn{3}{|c|}{$\begin{array}{l}\text { Mumbai } \\
\text { (Urban) }\end{array}$} & \multicolumn{2}{|c|}{$\begin{array}{l}\text { Gorakhpur } \\
\text { (Rural) }\end{array}$} \\
\hline & $\begin{array}{c}\text { GES+LSSM } \\
(n=333)\end{array}$ & $\begin{array}{c}\text { GES } \\
(n=321)\end{array}$ & $\begin{array}{c}\text { Comparison } \\
(\mathrm{n}=221)\end{array}$ & $\begin{array}{c}\text { GES } \\
(n=524)\end{array}$ & $\begin{array}{c}\text { Comparison } \\
(n=516)\end{array}$ \\
\hline Mean age (yrs) & 21 & 20 & 22 & 19 & 19 \\
\hline Married (\%) & 11 & 10 & 21 & 26 & 29 \\
\hline Education (median years) & 9 & 10 & 8 & 10 & 8 \\
\hline Employed (\%) & 70 & 57 & 79 & 31 & 45 \\
\hline $\begin{array}{l}\text { Mean age at first sex among those } \\
\text { sexually experienced (years) }\end{array}$ & 18 & 18 & 18 & 16 & 16 \\
\hline
\end{tabular}




\section{The Yaari-Dosti Intervention}

\section{Promoting Gender-equitable Norms and Behaviors}

Based on results from the formative research, as well as drawing on experiences addressing gender inequity in other cultural contexts, a peer-led, behavior change intervention targeted to young men was developed and piloted in an urban slum community in Mumbai by CORO and Horizons/Population Council. with support from Instituto Promundo. The peer leaders named the intervention Yaari-Dosti (YD) which means friendship, or bonding, between men. It was adapted from Program $\mathrm{H}$, an intervention designed for young men by Instituto Promundo and partners in Brazil and Mexico. Exposure to Program $\mathrm{H}$ in Brazil was found to lead to more gender-equitable attitudes and behaviors among young men, as well as increased condom use and decreased reported STI symptoms (Pulerwitz et al. 2006). The program was designed to stimulate critical thinking about gender norms that promote risky behavior and to create support for gender norms that promote care and communication. A gender-equitable man was defined as one who (1) supports relationships based on respect, equality, and intimacy rather than on sexual conquest, (2) is or seeks to be an involved domestic partner and father, both in terms of childcare and household activities, (3) assumes or shares with his partner reproductive health and disease prevention responsibilities, and (4) opposes intimate partner violence.

The India-adapted version of Program H involved implementation of peer-led group educational sessions in urban and rural settings and a lifestyle social marketing campaign adapted and field-tested in the urban settings for the Indian context.

\section{Peer-led Group Educational Sessions}

A total of 23 interactive group education activities adapted from Program $\mathrm{H}$ modules and piloted in Mumbai formed the basis of YD's group education sessions. Among the main themes covered in the exercises were gender and sexuality; STI/HIV risk and prevention; partner, family, and community violence; the reproductive system; alcohol and risk; and HIV-related stigma and discrimination. The group educational activities were peer led and used participatory methods of learning: role playing, games, and exercises that engaged young men in discussion, debate, and critical thinking.

In Mumbai, trained peer leaders from CORO, who had led the group educational activities in the pilot study, recruited 640 young men aged 16-28 years from the two slum communities for participation in the educational sessions in this evaluation. In Gorakhpur, 523 young men aged 15-24 years from one rural block were recruited by the trained peer leaders from DAUD to participate in the educational sessions.

In both the urban and rural sites, group education activities were implemented over an approximately sixmonth period. Young men met once every week, usually on Saturday or Sunday evenings. On average each session lasted for over one hour, and very often the discussions spilled over to the next session. The sessions led to intense discussion and debate. Young men often shared examples from their own life experiences, an indicator of the relevance of the methodology and the intervention themes.

Facilitators and field supervisors, together with gender experts, met once every month to discuss and share their experiences about program implementation. 


\section{Hgrizons}

\section{Lifestyle Social Marketing Campaign}

The LSSM campaign was carried out in the Mumbai community of Vashi Naka, where about 100,000 people live in a five square kilometer area. The major objective of the LSSM campaign was to reinforce the messages from the group educational sessions, which focused on more gender-equitable lifestyles and versions of manhood through community-based activities conducted in spaces where young men normally congregate. The campaign was developed and led by youth peer leaders from CORO using information gathered during the formative research phase and subsequent testing of messages by the youth leaders in the community. The campaign developed materials that used characters based on young men from these and similar communities. Table 4 lists the campaign's key themes and messages promoted.

\section{Table 4 Campaign themes and alternative views and behaviors promoted}

\begin{tabular}{|c|c|}
\hline Theme & $\begin{array}{l}\text { Positive alternatives that were promoted by the } \\
\text { LSSM campaign }\end{array}$ \\
\hline $\begin{array}{l}\text { Violence in intimate relationships, including } \\
\text { domestic violence }\end{array}$ & Relationships without violence \\
\hline $\begin{array}{l}\text { Men's sense of control and possessiveness over } \\
\text { women }\end{array}$ & Egalitarian and equitable attitudes \\
\hline $\begin{array}{l}\text { Perception of women as sex objects for men's } \\
\text { enjoyment }\end{array}$ & $\begin{array}{l}\text { A view of women and girls as human beings that } \\
\text { deserve to be treated with respect }\end{array}$ \\
\hline $\begin{array}{l}\text { Lack of responsibility in sexual relationships } \\
\text { leading to risky sexual behavior, including lack } \\
\text { of condom use }\end{array}$ & $\begin{array}{l}\text { Being accountable for and sharing responsibility for } \\
\text { reproductive and sexual health matters through } \\
\text { decreased risky sexual practices and increased } \\
\text { condom use }\end{array}$ \\
\hline
\end{tabular}

As part of the campaign, the peer leaders developed, pre-tested, and presented two street plays: one addressed violence and control, and the other examined the themes of women as sex objects, sexual risk behavior, and condom use. Five posters were designed to match the themes of the street plays: two reflected the themes of the first play and three focused on the themes of the second play. Each poster included the slogan, "Soch Sahi Mard vahi" ("A real man thinks right") and the logo of the campaign; they were pre-tested in the community before they were distributed to coincide with the street play performances.

In addition to posters, the campaign utilized pamphlets, comic strips, community-based discussions, and $\mathrm{t}$-shirts for projecting an alternative form of masculinity. A mobile booth served as a "dissemination point" for condoms as well as for communication materials in the community.

The plays, posters, and comic books used young male characters that acted in gender-equitable ways and questioned those men who did not. Rather than being accusatory, the messages and stories emphasized the advantages to men of being more gender equitable (e.g., more satisfying relationships with their wives and partners). 
Figure 1 Posters used in the campaign
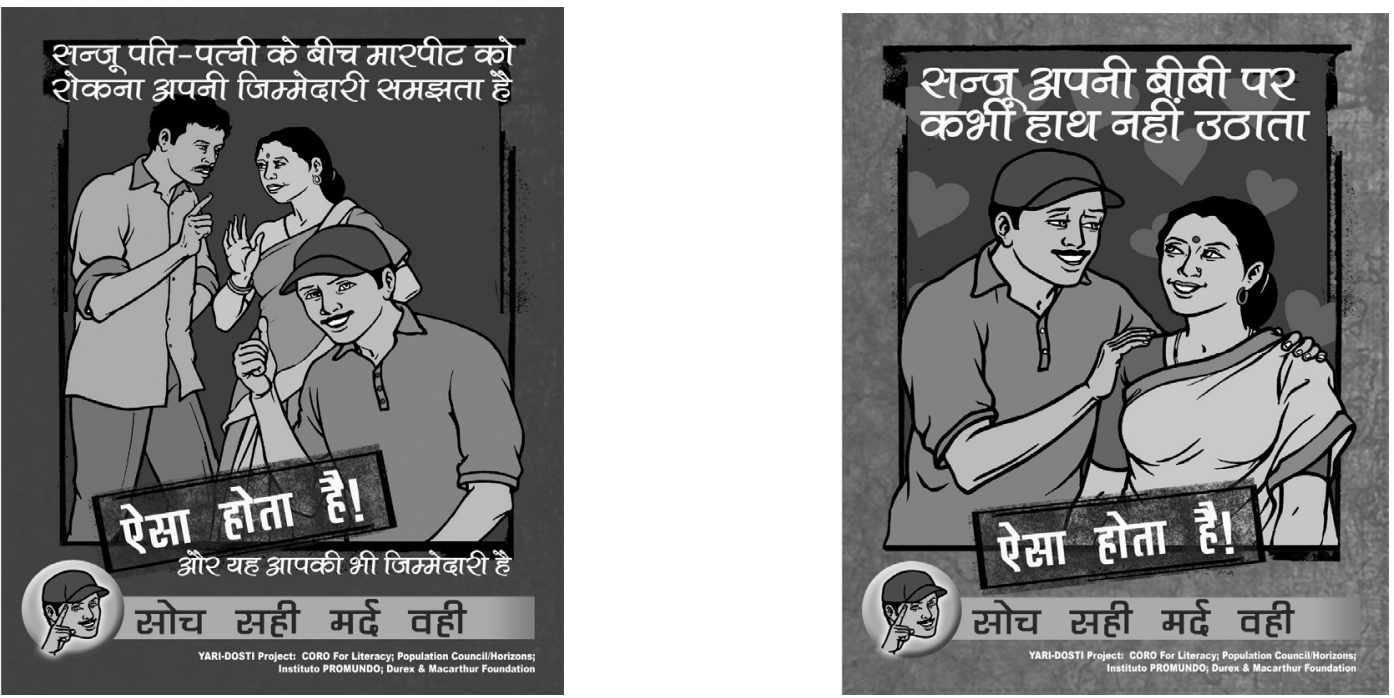

These two posters address the issue of domestic violence and suggest that it is men's responsibility to prevent it. 


\section{Hgrizons}

\section{Results}

\section{Baseline Results}

\section{The majority of young men supported inequitable gender norms.}

GEM scale scores were trichotomized into "high equity," "moderate equity," and "low equity." At baseline, less than 10 percent of the young men in all the sites were categorized as "highly equitable." The majority of young men were distributed across "moderate" and "low" equity categories. There was not much difference between the rural and urban sites (see Figure 2, page 20).

\section{Young men reported substantial HIV/STI risk practices at baseline.}

Table 5 summarizes the risk profile of respondents at baseline. Reports of at least one symptom indicative of poor sexual health - mainly STI symptoms - in the three months prior to the survey were substantial in all groups, but highest in the rural sites. Less than 10 percent of the young men had ever taken an HIV test. More than one-third of young men in both urban and rural sites reported that they had been physically or sexually violent against a sexual or non-sexual partner in the three months prior to the survey.

Across the urban sites, 44 percent of respondents were sexually experienced, with an average age of 18 years at sexual initiation. Young men from the rural area were somewhat more likely to be sexually experienced; 50 percent reported having had sex with any type of partner and their mean age of sexual initiation was 16 .

Of the young men in the urban sites who reported having had sex in the last three months, about onefourth of those in the GES+LSSM arm and less than half in the GES arm reported having had sex with two or more partners in that time period. In the rural sites, one-fourth of young men reported sex with two or more partners in the last three months. Close to 33 percent of the respondents in the GES+LSSM and comparison sites and 43 percent in the GES site in the urban setting reported condom use at last sex with all types of partners in the last three months. In the rural settings, this was reported by a little more than one-fourth of respondents. 
Table 5 Risk profile of participants at baseline by city and study arm

\begin{tabular}{|c|c|c|c|c|c|}
\hline & \multicolumn{3}{|c|}{ Mumbai } & \multicolumn{2}{|c|}{ Gorakhpur } \\
\hline & $\begin{array}{c}\text { GES+ } \\
\text { Campaign } \\
(n=197) \\
\%\end{array}$ & $\begin{array}{c}\text { GES } \\
(n=175) \\
\%\end{array}$ & $\begin{array}{c}\text { Comparison } \\
\text { (n=165) } \\
\%\end{array}$ & $\begin{array}{c}\text { GES } \\
\begin{array}{c}(n=300) \\
\%\end{array}\end{array}$ & $\begin{array}{c}\text { Comparison } \\
(\mathrm{n}=301) \\
\%\end{array}$ \\
\hline $\begin{array}{l}\text { Had at least one symptom of } \\
\text { poor sexual health during last } 3 \\
\text { months }\end{array}$ & 33 & 31 & 18 & 50 & 58 \\
\hline Ever tested for HIV & 9 & 6 & 9 & 3 & 1 \\
\hline $\begin{array}{l}\text { Sexually or physically violent } \\
\text { against any partner in the last } 3 \\
\text { months }\end{array}$ & 45 & 46 & 40 & 50 & 48 \\
\hline \multirow[t]{2}{*}{ Sexually experienced } & 44 & 45 & 41 & 54 & 46 \\
\hline & $(n=87)$ & $(n=79)$ & $(n=68)$ & $(n=161)$ & $(n=139)$ \\
\hline \multirow[t]{2}{*}{ Had sex in last 3 months } & 84 & 62 & 63 & 78 & 62 \\
\hline & $(n=73)$ & $(n=49)$ & $(n=43)$ & $(n=126)$ & $(n=86)$ \\
\hline $\begin{array}{l}\text { In last } 3 \text { months had sex with } \\
\geq 2 \text { partners }\end{array}$ & 27 & 43 & 7 & 23 & 23 \\
\hline $\begin{array}{l}\text { Condom use at last sex with all } \\
\text { partners in last } 3 \text { months }\end{array}$ & 34 & 43 & 30 & 29 & 28 \\
\hline
\end{tabular}

\section{Condom use varied by partner type.}

In the urban sites, among the men who reported sex with a casual partner (included casual female and male partners and sex workers), a majority reported condom use at last sex with these partners at baseline. The number of young men who had sex with a casual partner was quite small, and the results should be interpreted in that context. Of the men who had sex with regular partners (including a wife and/or a girlfriend), 60 percent of young men in the GES site reported using condoms at last sex as compared to only 40 percent in the GES+LSSM site and 29 percent in the comparison site. Condom use at last sex in the rural area was lower with both regular and casual partners than in the urban area (see Table 6). 
Table 6 Condom use during last sex at baseline by city and study arm

\begin{tabular}{lc|c|c|c|c}
\hline & \multicolumn{3}{c|}{ Mumbai } & \multicolumn{2}{c}{ Gorakhpur } \\
& $\begin{array}{c}\text { GES+LSSM } \\
\%\end{array}$ & $\begin{array}{c}\text { GES } \\
\%\end{array}$ & $\begin{array}{c}\text { Comparison } \\
\%\end{array}$ & $\begin{array}{c}\text { GES } \\
\%\end{array}$ & $\begin{array}{c}\text { Comparison } \\
\%\end{array}$ \\
\hline Condom use during last & 60 & 73 & 91 & 15 & 5 \\
sex with a casual partner & $\mathrm{n}=24$ & $\mathrm{n}=26$ & $\mathrm{n}=22$ & $\mathrm{n}=95$ & $\mathrm{n}=80$ \\
Condom use during last & 41 & 59 & 29 & 13 & 22 \\
sex with a regular partner & $\mathrm{n}=78$ & $\mathrm{n}=48$ & $\mathrm{n}=65$ & $\mathrm{n}=107$ & $\mathrm{n}=97$ \\
\hline
\end{tabular}

\section{Support for inequitable gender norms was associated with HIV risk.}

At baseline, young men who were the least gender equitable based on GEM Scale scores were more likely to report HIV risk behaviors. Combined data from the three urban sites indicate that young men who supported inequitable norms were significantly $(\mathrm{p}<.05)$ less likely to use condoms and more likely to report symptoms of poor sexual health. In rural sites, there was a significant association $(\mathrm{p}<.05)$ between support for inequitable norms and reporting at least one symptom of poor sexual health, partner violence, and sex with more than one partner.

\section{Post-intervention Results}

\section{Intervention participants reported less support for inequitable gender norms after the intervention.}

The GEM Scale was administered to all participants at baseline and follow up. The baseline results from each site are presented in Table 7. Also indicated in the table are whether there were significant changes in responses to each item (either increased or reduced support) by site from baseline to follow up.

In the GES+LSSM urban site, a total of 9 of 15 adapted GEM Scale items changed significantly $(\mathrm{p}<.05)$ in the positive direction, that is, toward more support for equitable gender roles. Four of five items in the sexuality domain showed improvement and three of four items in the domestic life and child care domain improved. One of three items improved under both the reproductive health and disease prevention domain and the violence domain. It is worth noting that two of three violence domain items shifted in a negative direction. Three items showed no significant change in either direction.

At follow up in the urban GES arm, a total of 7 of 15 items changed significantly in the positive direction, two items changed significantly in the negative direction, and six items showed no significant change in either direction. In this group, all four items in the domestic life and child care domain changed in the positive direction, while each of the other domains showed improvement in one item each. The two negative shifts were found in the violence domain.

While there was substantial positive change in both of the intervention arms, a similar degree of positive change was not observed in the comparison arm. In this arm, only 2 of 15 items changed in the positive direction, six items changed in the negative direction, and seven items showed no significant change. 
In the rural sites, there was also substantial positive change in the intervention arm that was not found in the comparison arm. In the intervention arm, 9 of 15 items changed in the positive direction, two in the negative direction, and four items showed no significant change. In contrast, in the comparison group, there were no shifts toward more positive gender attitudes and behaviors in the rural comparison group: five items shifted in the negative direction while 10 items showed no significant change in either direction.

\section{Table 7 Percent of men agreeing with GEM Scale items at baseline and significant} changes in items from baseline to follow up by city and study arm

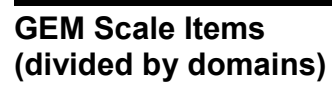

(divided by domains)

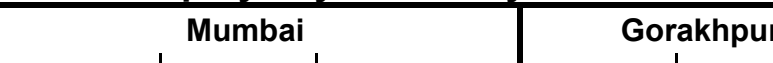

\begin{tabular}{|c|c|c|c|c|c|}
\hline & $\begin{array}{c}\text { campaign } \\
\text { (n = 197) } \\
\% \text { Agree }\end{array}$ & $\begin{array}{l}(n=175) \\
\% \text { Agree }\end{array}$ & $\begin{array}{l}\text { (n = 165) } \\
\% \text { Agree }\end{array}$ & $\begin{array}{l}(n=300) \\
\% \text { Agree }\end{array}$ & $\begin{array}{l}(n=301) \\
\% \text { Agree }\end{array}$ \\
\hline \multicolumn{6}{|l|}{ Reproductive health and disease prevention } \\
\hline $\begin{array}{l}\text { It is woman's responsibility to avoid getting } \\
\text { pregnant }\end{array}$ & 51 & $59 *$ & $41 * *$ & 51 & $48 * *$ \\
\hline $\begin{array}{l}\text { I would be outraged if my wife asked me to use a } \\
\text { condom }\end{array}$ & 36 & 43 & 35 & 25 & 22 \\
\hline A real man produces a male child $(\mathrm{I})$ & $41 *$ & 47 & $46 * *$ & $31 * *$ & $41 * *$ \\
\hline \multicolumn{6}{|l|}{ Sexuality } \\
\hline Men need more sex than women do & $59 *$ & 64 & $44 * *$ & 50 & 59 \\
\hline You don't talk about sex, you just do it & $40 *$ & 45 & 40 & $24 *$ & $21 * *$ \\
\hline Men are always ready to have sex & $59 *$ & $64^{*}$ & 44 & 39 & 54 \\
\hline $\begin{array}{l}\text { Men need other women even if the things with his } \\
\text { wife are fine }\end{array}$ & 40 & 51 & 36 & $26 *$ & $25^{\star *}$ \\
\hline $\begin{array}{l}\text { A real men is one who can have sex with a woman } \\
\text { for a long time (I) }\end{array}$ & $63 *$ & 57 & 61 & $50 *$ & 40 \\
\hline \multicolumn{6}{|l|}{ Violence } \\
\hline $\begin{array}{l}\text { It is okay for a man to hit his wife if she won't have } \\
\text { sex with him }\end{array}$ & $24 * *$ & $29 * *$ & $37 *$ & $27^{*}$ & 22 \\
\hline $\begin{array}{l}\text { A woman should tolerate violence in order to keep } \\
\text { her family together }\end{array}$ & $71^{*}$ & $68 *$ & $59 * *$ & 85 & 85 \\
\hline $\begin{array}{l}\text { There are times when a woman deserves to be } \\
\text { beaten }\end{array}$ & $33^{* *}$ & $39 * *$ & $44^{* *}$ & $79 *$ & 75 \\
\hline \multicolumn{6}{|l|}{ Domestic life and child care } \\
\hline $\begin{array}{l}\text { A man should have the final word about decisions } \\
\text { in his home }\end{array}$ & 73* & $67 *$ & 64 & $76 *$ & 78 \\
\hline $\begin{array}{l}\text { Giving the kids a bath and feeding the kids are the } \\
\text { mother's responsibility }\end{array}$ & $94 *$ & $91 *$ & 73 & $79 *$ & $75^{* *}$ \\
\hline $\begin{array}{l}\text { A man is happily married only if his wife brings a } \\
\text { big dowry (I) }\end{array}$ & $10 * *$ & $15^{*}$ & $16 * *$ & $11 *$ & 6 \\
\hline $\begin{array}{l}\text { A married woman should not need to ask her } \\
\text { husband for permission to visit her parents/family (I) }\end{array}$ & $39 *$ & $24 *$ & $51 *$ & 85 & 96 \\
\hline
\end{tabular}

*Indicates a significant $(p<0.05)$ positive change, that is, toward more support for equitable gender norm attitudes and behaviors when comparing baseline and follow-up results.

${ }^{* *}$ Indicates a significant $(p<0.05)$ negative change, that is, toward less support for equitable gender norms and attitudes and behaviors when comparing baseline and follow-up results. 


\section{Hgrizons}

In order to more easily interpret changes in support for gender equity, each respondent's GEM Scale score was categorized as "low equity," "moderate equity," or "high equity." The analysis indicates a significant positive shift $(\mathrm{p}<0.05)$ from the low equity category to the moderate and high equity categories in all intervention areas; with the most significant changes occurring in Mankhurd in Mumbai (urban GES). Changes in the comparison groups were not significant (see Figure 2.)

Figure 2 Changes in GEM Scale categories by city and study arm

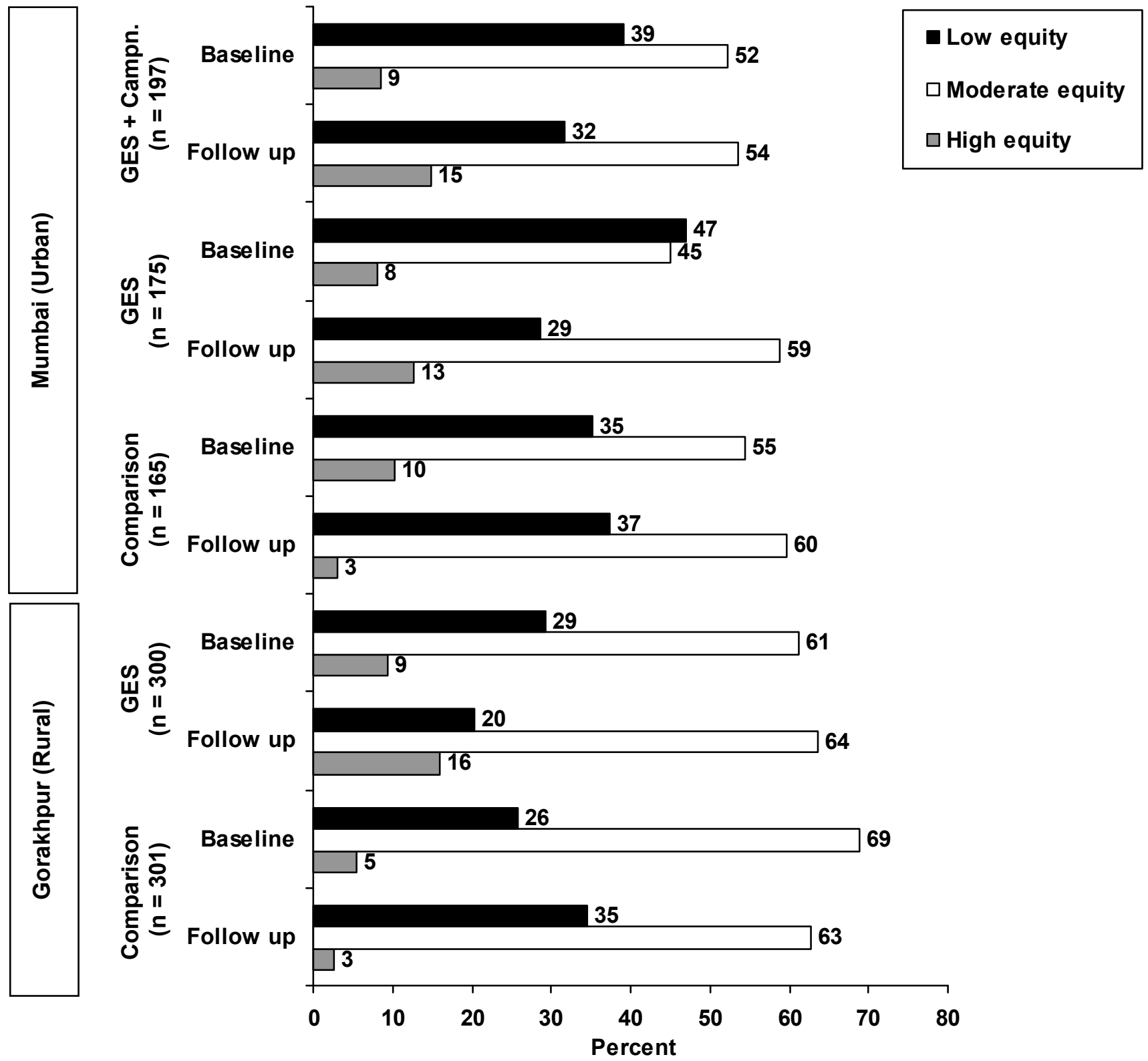


In the third analysis of the changes in GEM Scale scores from baseline to follow up, the mean GEM Scale score for each study site was calculated. While the mean scores improved significantly $(p<0.05)$ in the two urban intervention sites in Mumbai and the rural intervention site in Gorakhpur, mean scores worsened significantly in the comparison site in Mumbai. There was no significant change in the mean score in the rural comparison site. At follow up, the difference in mean scores between the intervention sites (both urban and rural sites) and the comparison sites was also significant (ANOVA test; $p<0.05$ ), with the intervention sites having higher scores than the comparison sites. There was no significant difference between the three intervention sites in the mean GEM Scale scores.

Changes in attitudes were positively correlated with intervention participation. The young men in the intervention arms in both the urban and rural settings were two times more likely to have positive changes in GEM Scale scores compared to young men in the comparison sites $(\mathrm{p}<.05)$.

\section{Communication with partners on condoms, sex, STIs, and/or HIV significantly improved in the intervention sites.}

There were significant improvements among the intervention participants at all sites in discussing key reproductive and sexual health issues with a female partner in the last three months (see Figure 3). After the intervention, young men in all three of the intervention sites who had a female partner (either sexual or non-sexual) were significantly more likely $(\mathrm{p}<.05)$ to have talked to her about one or more of the following themes: condom use, sexual relationships, STIs, and HIV/AIDS.

In both urban intervention sites the number of men discussing any one of these topics with a partner increased by almost one and a half times from baseline to follow up, while it decreased in the comparison site. The number of men communicating about any of these topics with a partner more than doubled in the rural intervention arm. However, it also more than doubled in the comparison arm.

Figure 3 Changes in partner communication about condoms, sex, STIs, and/or HIV in the last three months by city and study arm

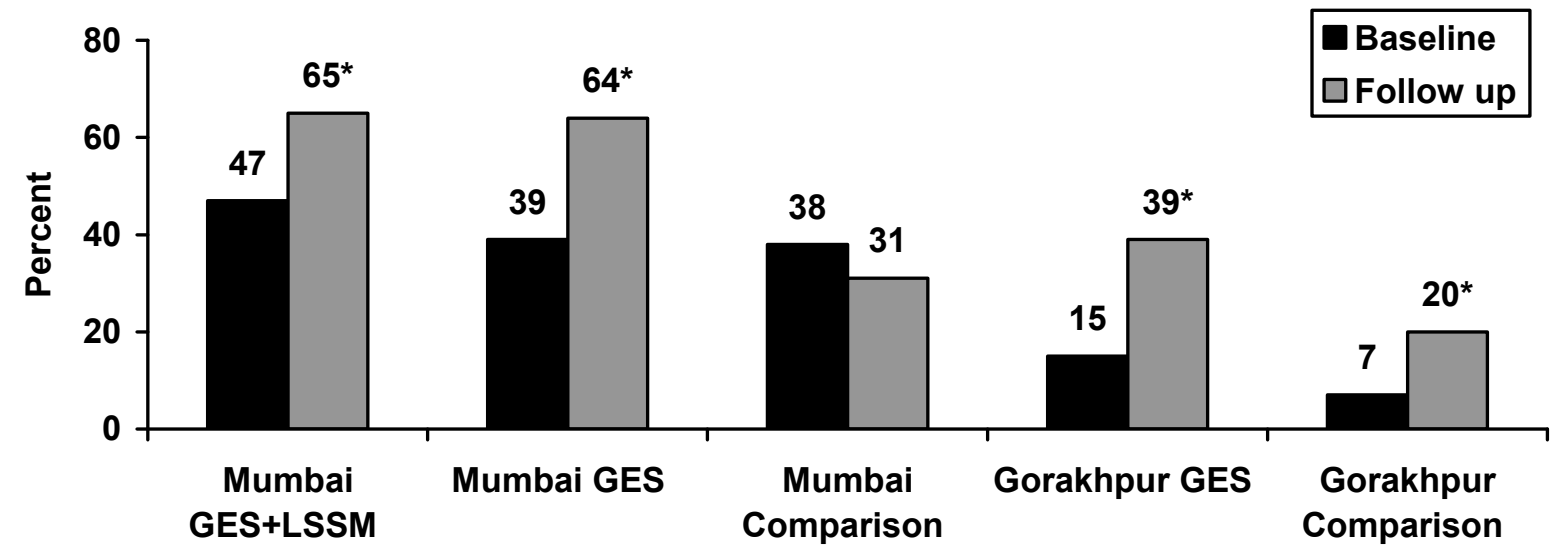

Note: Mumbai GES+LSSM: Baseline $n=129$, Follow up $n=99$; Mumabi GES: Baseline $n=109$, Follow up $n=81$; Mumbai comparison: Baseline $n=71$, Follow up $n=103$; Gorakhpur GES: Baseline $n=210$, Follow up $n=202$; Gorakhpur comparison Baseline $n=202$, Follow up $n=172$ ${ }^{*} p<0.05$ 


\section{Hgrizons}

There was a significant increase in condom use at last sex with all partner types in the intervention areas.

Among the young men who had sex in the last 3 months, condom use at last sex with all sexual partners increased significantly $(\mathrm{p}<0.05)$ in the urban and rural intervention sites from baseline to follow up (see Figure 4). In particular, condom use at last sex almost doubled in the GES urban site and the GES rural site, and more than doubled in the GES+LSSM urban site. In contrast, condom use stayed the same in the comparison sites.

Figure 4 Changes in condom use at last sex in the last 3 months with all partners by city and study arm

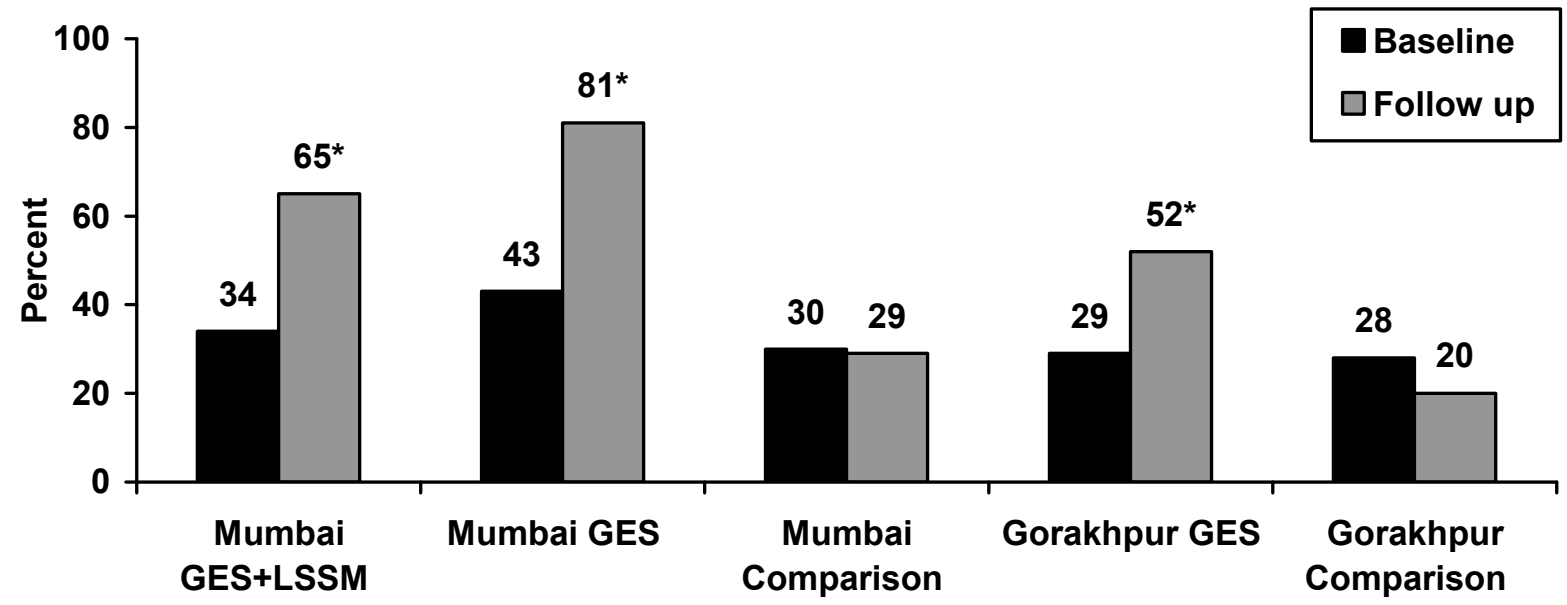

Note: Mumbai GES+LSSM: Baseline $n=73$, Follow up $n=68$; Mumabi GES: Baseline $n=49$, Follow up $n=42$; Mumbai Comparison: Baseline $n=43$, Follow up $n=69$; Gorakhpur GES: Baseline $n=126$, Follow up $=120$; Gorakhpur Comparison: Baseline $\mathrm{n}=86$, Follow up $=96$ ${ }^{*} p<0.05$

Logistic regression analysis at follow up (see Table 8) revealed that the likelihood of condom use at last sex in last three months with all partner types was three times higher in Mumbai $(\mathrm{p}<0.001)$ and 4.5 times higher in Gorakhpur $(\mathrm{p}<.001)$ among the young men who discussed either condom use, sex, STIs, or HIV/AIDS with a partner as compared to those who did not discuss any of these topics. In addition, those men classified as highly equitable at follow up (based on GEM Scale scores) were $1.6(p=0.03)$ and 1.9 $(p=0.02)$ times more likely to use condoms at last sex in Mumbai and Gorakhpur, respectively, than those who were classified as the least equitable. Men in the intervention arms were 1.9 times more likely to have used condoms at last sex in Mumbai $(\mathrm{p}<0.001)$ and 2.8 times more likely to have used them in Gorakhpur $(\mathrm{p}<0.001)$ than those in the comparison arms in each setting. 
Table 8 Multiple logistic regression results at follow up for condom use at last sex in last 3 months with all partner types by city

\begin{tabular}{|c|c|c|c|c|}
\hline \multirow[t]{2}{*}{ Characteristics } & \multicolumn{2}{|c|}{ Mumbai (urban) $n=179$} & \multicolumn{2}{|c|}{ Gorakhpur (rural) $n=216$} \\
\hline & Odds Ratio & p-value & Odds Ratio & p-value \\
\hline \multicolumn{5}{|c|}{ Partner communication } \\
\hline No & - & - & - & - \\
\hline Yes & 3.122 & 0.000 & 4.450 & 0.001 \\
\hline \multicolumn{5}{|c|}{$\begin{array}{l}\text { GEM Scale category } \\
\text { (based on score) }\end{array}$} \\
\hline Low equity & - & - & - & - \\
\hline Moderate equity & 1.384 & 0.119 & 1.740 & 0.142 \\
\hline High equity & 1.578 & 0.027 & 1.899 & 0.021 \\
\hline \multicolumn{5}{|l|}{ Study arm } \\
\hline Comparison & - & - & - & - \\
\hline Intervention & 1.913 & 0.001 & 2.776 & 0.001 \\
\hline
\end{tabular}

${ }^{\S}$ Controlling for education, age, occupation, and marital status

\section{Self-reported violence against a partner declined in the intervention sites.}

The proportion of men in the urban intervention sites who reported violence against a partner (either sexual or non-sexual) in the last three months declined more than two fold to less than 20 percent $(\mathrm{p}<$ 0.05). There was a significant decrease from 50 percent to 37 percent of rural respondents in the intervention arm who reported partner violence at follow up. Reported partner violence actually increased significantly in both the urban and rural comparison groups (see Figure 5). 
Figure 5 Changes in self-reported partner violence in last 3 months by city and study arm

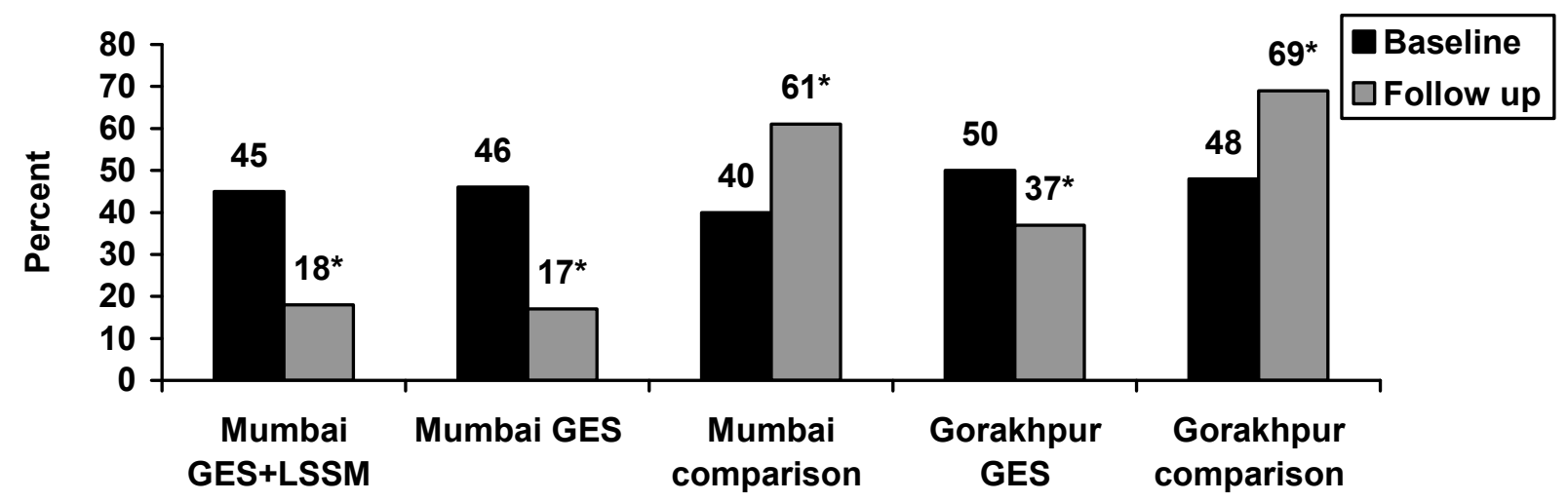

Mumbai GES+LSSM: Baseline $n=129$, Follow up $n=100$; Mumbai GES: Baseline $n=109$, Follow up $n=81$; Mumbai comparison: Baseline $n=71$, Follow up $n=103$; Gorakhpur GES: Baseline $n=211$, Follow up $n=203$; Gorakhpur comparison: Baseline $n=$ 203, Follow up $n=173$ ${ }^{*} p<0.05$

Logistic regression analysis (see Table 9) revealed that young men exposed to the intervention in Mumbai and Gorakhpur were about five times and two times less likely, respectively, to report partner violence ( $p$ $<.001$ ). Likewise, highly equitable young men (based on GEM Scale scores) were less likely to be violent with their partners in Mumbai and in Gorakhpur $(\mathrm{p}=0.032, \mathrm{p}=0.004$, respectively). Young men who discussed such themes as condoms, sex, STIs, and/or HIV with a partner were three times less likely to be violent in Gorakhpur ( $\mathrm{p}<0.001$ ), but no statistically significant association was seen in Mumbai.

Table 9 Multiple logistic regression results for physical or sexual violence against a partner in the previous 3 months by city ${ }^{\S}$

\begin{tabular}{lcccc}
\hline Characteristics & \multicolumn{2}{c}{ Mumbai (urban) $\mathbf{n}=\mathbf{2 8 4}$} & \multicolumn{2}{c}{ Gorakhpur (rural) $\mathbf{n}=\mathbf{3 7 6}$} \\
& Odds Ratio & $\mathbf{p}$-value & Odds Ratio & p-value \\
\hline Partner communication & & & & \\
$\quad$ No & - & - & - & - \\
$\quad$ Yes & 0.699 & 0.269 & 0.315 & 0.001 \\
GEM Scale category (based on score) & & & & - \\
$\quad$ Low equity & - & - & - & - \\
$\quad \begin{array}{l}\text { Moderate equity } \\
\text { High equity }\end{array}$ & 0.785 & 0.071 & 0.725 & 0.025 \\
Study arm & 0.691 & 0.032 & 0.445 & 0.004 \\
$\quad \begin{array}{l}\text { Comparison } \\
\text { Intervention }\end{array}$ & & & & - \\
\hline
\end{tabular}

${ }^{\S}$ Controlling for education, age, occupation, and marital status 
During in-depth interviews conducted with a sub-sample of young men after they participated in the group educational activities, they discussed how the sessions helped them to change their behavior toward their partner and other women.

As far as the sexual act is concerned, if my wife is uncomfortable I do not force her now, earlier I used to.... Because of the participation in YD program I have started respecting the feelings of my wife.

My sister told me that her friends informed her that "your brother has changed, now he talks very differently and does not use vulgar language." Yes now I talk very respectfully to them whenever I meet them.

\section{Report of sexual health problems during the previous three months decreased significantly in the intervention sites but not in the comparison sites.}

The young men in all of the three intervention arms reported a significant decrease in sexual health problems from baseline to follow up $(\mathrm{p}<0.05)$. However, there were no significant improvements in the comparison sites (see Figure 6).

Figure 6 Changes in proportion of respondents reporting at least one sexual health problem by city and study arm

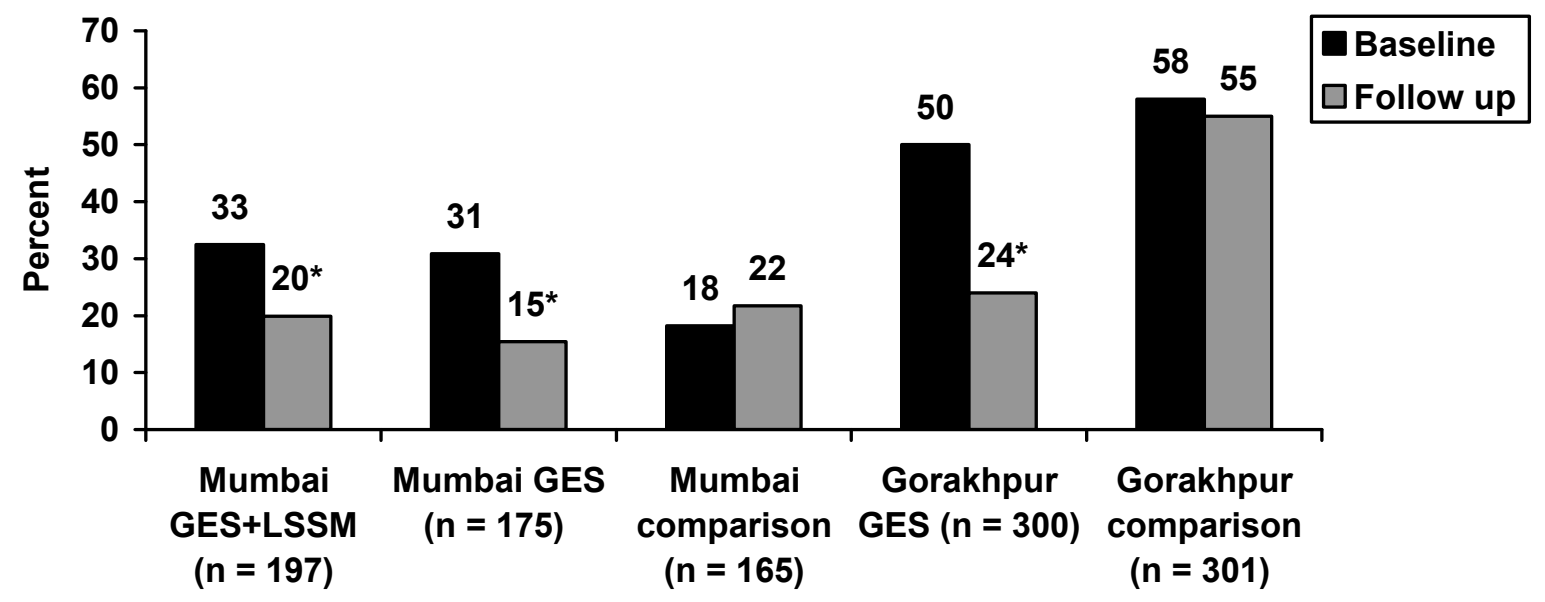

${ }^{*} \mathrm{p}<0.05$

There was a positive trend toward improvements in GEM Scale scores being associated with decreases in HIV/STI risk behaviors.

Analyses were conducted to determine if there was a correlation between positive changes in attitudes among respondents (calculated by subtracting the GEM Scale score at follow up from the baseline GEM Scale score) and reductions in HIV risk behaviors. Although these correlations were not statistically significant, there was some change in the right direction. For example, young men in the rural sites who 


\section{Hgrizons}

improved their GEM Scale scores at follow up were 1.2 times more likely to have used condoms at last sex than those without GEM Scale score improvements.

Comments from young men during in-depth interviews supported the relationship between increased support for gender equity and risk reduction. One young married man reported that since participating in the YD program, he started to respect his wife and communicate more with her, and stopped engaging in multi-partner, extramarital sex.

After the session on gender and discussions with the peer leaders, I realized the importance of my wife. Slowly, slowly I started discussing with her, started helping in her work and this has created more love and affection between us. I started respecting her and one day she requested me to keep away from my girlfriends and do not bring them in the house. I have accepted it, initially it was very difficult for me, but now I have completely stopped meeting with the girlfriends.

Young married man

\section{Young men in the intervention sites reported more positive attitudes toward PLHIV.}

For the baseline and follow-up surveys, young men's responses on the statements about attitudes toward PLHIV were totaled and scored. If the follow-up score was higher than the baseline score, it was considered to be a positive change or improvement in attitudes toward PLHIV. As shown in Figure 7, young men in the intervention arms showed significant improvements in their attitudes toward PLHIV. However, attitudes toward PLHIV significantly worsened among the comparison groups in both Mumbai and Gorakhpur

Figure 7 Changes in positive attitudes toward PLHIV by city and study arm

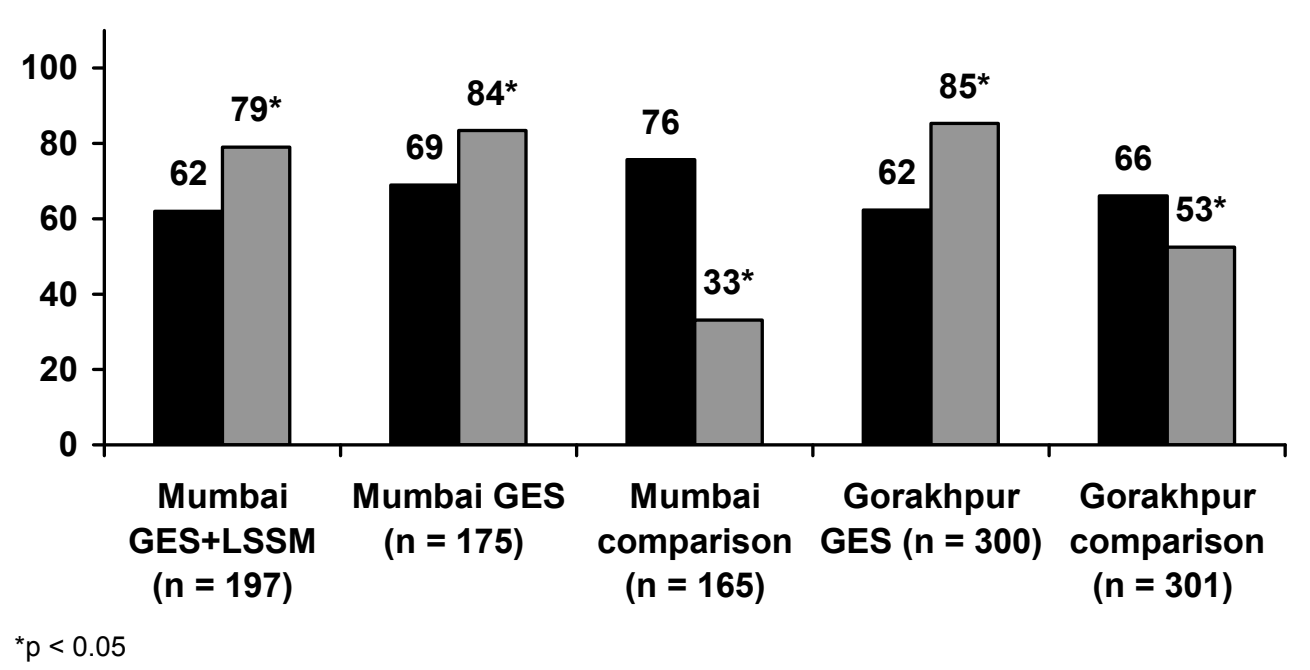

Baseline

Follow up

Young men participated actively in the group education sessions.

As shown in Figure 8, about seven in 10 intervention participants attended at least 11 (about half) of the 23 sessions. Some of the most well attended sessions, with over 70 percent attendance in all three sites, 
were: "STI and HIV," "Me and my body," "Power and violence," "Testing and counseling," "I am HIVpositive," "Condom use," "What is Gender," and "Sexuality and Reproduction." Some participants highlighted the usefulness of the sessions and their impact on their everyday lives.

I have got very useful information about HIV/AIDS from the Yaari-Dosti Project and I am sharing it with my friends and helping them to protect themselves from this dangerous illness. In this way, somehow, I have also developed a kind of leadership by sharing this knowledge. Some of my friends do not accept it but still I am trying to convince them.

21 year-old unmarried man

After the program I can say that I got good information on issues of gender roles and discriminations, sexual violence, sexuality, addiction, HIV/AIDS, etc. I have shared everything with my wife that has resulted in us coming more close to each other.

22 year-old married man

One respondent explained the volatile nature of discussions in the group sessions that were useful in allowing all participants to share their feelings and discuss matters openly.

Sometimes there were clashes in the group because some group members did not agree with the gender discrimination being discussed and the other group members agreed that there was discrimination. Then the peer leader would ask us questions and provide examples to help the group discuss these issues and would ask us to decide on our stand without forcing his opinions on us. That situation was really enjoyable and in some cases all of us would not always agree. These discussions have helped a lot of us in many ways and it has benefited me very much because I am now applying these issues in my family and also with my girlfriend.

23 year-old unmarried man

Figure 8 Attendance at group education sessions in intervention sites

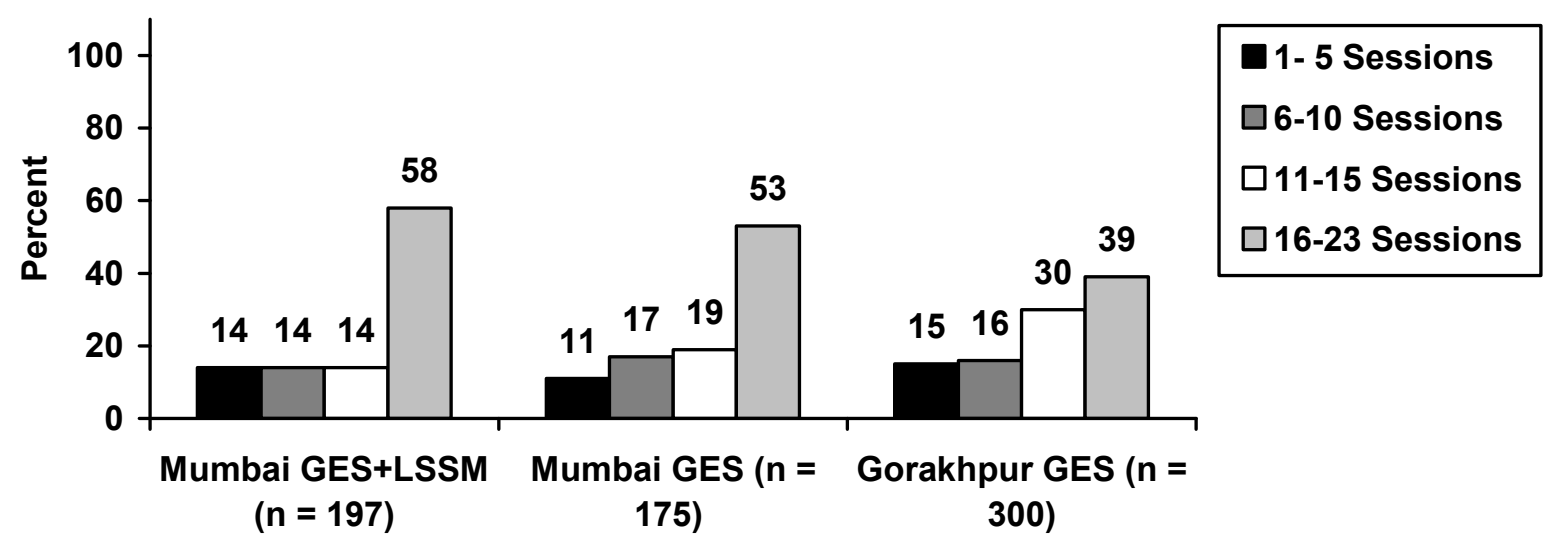

At the end of the group educational sessions, some of the young men discussed how their attitudes changed over the course of the YD program, and the facilitators summarized their observations. Based on these observations, the young men often started with denial of or justification of gender inequity, then after some sessions, moved on to understanding and acceptance of the existence of these imbalances. 


\section{Hgrizons}

Then many of the young men decided to make or made changes in their attitudes and behaviors. In the words of some of the participants:

Yes, my family used to restrict my sister but that was because she is not well educated. Also being an elder brother, I feel that nothing should go wrong with my sister and that is why I take care of her. But now I understand that restrictions should be reduced and girls or women should be given an opportunity to build their confidence for doing outside work alone, otherwise she will not be able to do it and always feel insecure without accompanied persons. I am now giving my sister freedom and don't always stop her from going out with her friends.

21 year-old unmarried man

Gender difference is the creation of nature so if I was differentiating for some time that is also quite natural. Earlier when I used to go out with my friends, then I used to also tease girls using vulgar words. But after participating in Yaari-Dosti, my thoughts have changed. I feel now that the girls who are teased by the young boys suffer a lot. We should respect them. Also, earlier I used to make comments and write lines on how girls dress up and expose their bodies. Now I feel very ashamed that I had written these lines. I have changed my thoughts now and have realized that it is not about how the woman dresses but it is the way we men look at the woman that is the key.

22 year-old unmarried man

When we joined the program we never realized that a lot of our acts were violent acts toward our women. We used to think that during sex if a woman does not cry then she is not satisfied and so we used to make her cry, or we used bad words when talking about girls. Touching their bodies, pressing the breasts, beating the girlfriend or wife are all normal ways to behave with girls and women. If the woman watches too much of $T V$ serials, does not listen to her husband, shares sexual relations with others, does not respect or shouts at parents-in-laws, etc., these are the common reasons for wife beating. However, after the discussions in the sessions we realized that these are forms of violence acts while we were treating these acts as customary acts. But now we have realized and came to know the real definition of violence and understand that violence and beating is not an alternative but we should understand and respect women. We thank the peer leaders and the Yaari-Dosti program for making us aware of this violence in our lives.

Young male participant in a group discussion 


\section{Discussion and Conclusions}

The results of this study indicate that young men became less supportive of inequitable gender norms after participating in the interventions, whereas in the comparison groups, there tended to be little or no positive changes, or the changes were in the wrong direction. Similarly, there were significant improvements among intervention participants - but not participants in the comparison groups - in key outcome indicators, including condom use, partner communication, partner violence, and attitudes toward PLHIV. The evidence suggests that including a gender focus in HIV prevention and care programs with young men is a successful strategy, and one that should be regularly taken into account.

In Mumbai, two different interventions were compared, and this study revealed no significant differences in outcomes between the two groups. While the similar study in Brazil demonstrated greater impact of the combined intervention (group sessions plus a lifestyle social marketing program) on some indicators (Pulerwitz et al. 2006), here the GES group did as well as the GES+LSSM in terms of improvements in attitudes and behaviors. This does not demonstrate that the campaign in Mumbai was ineffective, as the study design did not permit an evaluation of the impact of the campaign component alone. But the data do show the value of group education among men in the study communities. Based on this study's successful results, project collaborators are now proceeding to scale up the Yaari-Dosti program in India's public education sector.

In regards to the India-adapted GEM Scale, a multi-stage process was used to ensure that the items were relevant in the Indian context, and the psychometric evaluation suggests that the adapted scale is reliable and valid. Positive change in overall scale scores was clearly measured for the intervention participants, while similar change was not seen among comparison group participants. In terms of change on specific items and domains within the scale, the domain of domestic life and child care seemed to fare best overall, with three of the four items shifting in the positive direction in all intervention sites. On the other hand, changes in the violence domain were inconsistent, as two of the three items shifted in the negative direction in each of the three arms in Mumbai, while this negative shift was not seen in the rural site, Gorakhpur. Nevertheless, the study did document a significant reduction in reported partner violence among intervention groups in both regions, whereas there was a significant increase in reported violence among respondents in the comparison groups. Whether both the positive and negative reported changes in attitudes and behaviors represent social desirability bias or true change is not clear. Perhaps, for example, a reduction in reported violence among intervention participants and increase among comparison group participants is due to increased awareness of violence among all participants but a lack of exposure to subsequent intervention activities in the comparison group. Findings from the qualitative data support positive reductions in physical and verbal abuse by men who took part in the interventions.

It is clear that attitudes toward violence are deeply rooted and thus may be more difficult to change. Study findings indicate that men perceive violence as a tool to control women and justify it through various reasons. Recent data from the National Family Health Survey (Round 3) in India show that 40 percent of ever-married women had experienced physical, sexual, or emotional violence from their spouse. The data also show that the prevalence of violence among women who report that a husband beating his wife is justified in at least one situation is 41-44 percent, as compared to 30 percent among women who state there is no reason that can justify this kind of violence (IIPS and Macro International 2007). To best address violence against women in this context, programs should include a substantial proportion of violence reduction activities plus sufficient time and space for discussions on these issues. Further, programs should find ways to work with couples in addition to working with men and women separately. 


\section{Hgrizons}

The evaluation of the program found a number of positive changes, but the question that naturally follows is, how sustainable are these changes? One would need to follow these young men for a considerable amount of time to assess the strength and sustainability of changes in their attitudes and reported behaviors. In the similar study in Brazil, positive changes were maintained during the follow-up data collection period, six months after the intervention ended (and were not seen among the comparison group). In the current context, the prevailing masculinity norms and expectations from men to behave in a stereotypical manner are generally strong and operate in a variety of subtle yet profound manners. There is an obvious need to regularly reinforce the messages of alternative forms of masculinity, and to continue to support normative change through an "enabling" environment. It will be important to build alliances for large scale and ongoing discourse on men and masculinities. An immediate response that is recommended is explicit inclusion of discussions of manhood and masculinities in educational activities and the promotion of critical reflection about violence and manhood.

There are limitations of this study that should be noted. First, given the self-selection of the study participants, they may be more likely to change than those who did not join. Second, outcome measures relied on self-reports of participants. It is possible that participants sometimes gave what they felt were the "correct" or "desirable" answers. Examples of ways to strengthen findings in future studies include the use of a research design with group randomization, the use of additional outcome measures such as biological markers for STI infection, and/or the inclusion of interviews with partners of participants to confirm change reported by the participants.

While findings suggest that the interventions were successful in a variety of ways, the study showed that change in attitudes and behaviors is a complex process. Not everyone who attended the program changed in a positive direction, and most changed from the "low equity" to the "moderate equity" level as measured by the GEM Scale, with few men shifting into the "high equity" category. Qualitative observation of those who attended the sessions showed that changes among men happened in stages. In the initial stages of the intervention, young men who came into the sessions often denied the idea of gender-based inequality in their society and in their individual actions. As they progressed through the sessions, they moved their position toward accepting that gender-based inequality did exist and that their attitudes and behaviors were gender inequitable. Finally, participants acknowledged that change was worthwhile for themselves, their partners, and the greater society. Promoting gender equity takes ongoing effort, but led to some important changes that resulted in reduced HIV risk for the young men and their partners. 


\section{References}

Amaro, H. 1995. "Love, sex, and power: Considering women's realities in HIV prevention," American Psychologist 50(6): 437-447.

Archer, J. 1984. "Gender roles as developmental pathways," British Journal of Social Psychology 23: 245-256.

Barker, G. 2000a. What About Boys? A Review and Analysis of International Literature on the Health and Developmental Needs of Adolescent Boys. Geneva: World Health Organization.

2000b. "Gender equitable boys in a gender inequitable world: reflections from a qualitative research and program development with young men in Rio de Janeiro, Brazil," Sexual and Relationship Therapy 15(3): 263-282.

Bruce, J., C. Lloyd, and A. Leonard. 1995. Families in Focus: New Perspectives on Mothers, Fathers, and Children. New York: Population Council.

Childhope. 1997. "Gender, sexuality and attitudes related to AIDS among low income youth and street youth in Rio de Janeiro, Brazil," Childhope Working Paper no. 6. New York: Childhope.

Devasia, L. 1991. Girl Child in India. New Delhi: Ashish Publishing House.

Erikson, E. 1968. Identity: Youth and Crisis. New York: W.W. Norton.

Greene, Margaret E. 1997. "Watering the neighbors' garden: Investing in adolescent girls in India," South and East Asia Regional Working Paper no. 7. New Delhi, Population Council.

Greene, Margaret E. et al. 2004. "Involving men in reproductive health: Contributions to development," paper prepared for United Nations Millennium Project. New York: United Nations.

International Institute for Population Sciences (IIPS) and Macro International. 2007. National Family Health Survey (NFHS-3), 2005-06: India: Volume I. Mumbai: IIPS

Marsiglio, W. 1988. "Adolescent male sexuality and heterosexual masculinity: A conceptual model and review," Journal of Adolescent Research 3(3-4): 285-303.

Mensch, B., J. Bruce, and M. Greene. 1998. The Uncharted Passage: Girls'Adolescence in the Developing World. New York: Population Council.

Morris, L. 1993. "Determining male fertility through surveys: Young adult reproductive health surveys in Latin America," presented at the General Conference of the IusSP, Montreal, Canada.

National AIDS Control Organization (NACO) 2007. Accessed 22 February 2008 at: http://www.nacoonline.org. 


\section{Hgrizons}

Pelto, P.J., A. Joshi, and R. Verma. 1999. "Development of sexuality and sexual behavior among Indian males: implications for the reproductive health program," paper prepared for "Enhancing the roles and responsibilities of men in sexual and reproductive health,"New Delhi: Population Council.

Population Council. 2001. "The unfinished transition: Gender equity: Sharing the responsibilities of parenthood," Population Council Issues Paper. New York: Population Council.

Pulerwitz, J. et al. 2002. "Relationship power, condom use, and HIV risk among women in the US," AIDS Care 14(6): 789-800.

Pulerwitz, J. et al. 2006. "Promoting more gender-equitable norms and behaviors among young men as an HIV/AIDS prevention strategy," Horizons Final Report. Washington, DC: Population Council.

Pulerwitz and Barker. 2008. "Measuring attitudes toward gender norms among young men in Brazil: Development and psychometric evaluation of the GEM Scale," Men and Masculinities 10: 322-338.

Rivers, K. and P. Aggleton. 1999. Men and the HIV Epidemic, Gender and the HIV Epidemic. New York: UNDCP HIV and Development Program.

UNAIDS. 1999. Gender and HIV/AIDS: Taking Stock of Research and Programs. Geneva: UNAIDS.

Verma, R.K. and V.S. Mahendra. 2004. "Construction of masculinity in India: a gender and sexual health perspective," Indian Journal of Family Welfare 50(Special issue): 71-78.

Verma, R.K. et al. 2005. "From research to action — addressing masculinity and gender norms to reduce HIV/AIDS related risky sexual behavior among young men in India," Indian Journal of Social Work (Special Issue).

Verma, R.K. et al. 2006. "Challenging and changing gender attitudes among young men in India," Reproductive Health Matters 14(28): 1-10.

Weiss, E., D. Whelan, and G.R. Gupta. 2000. "Gender, sexuality and HIV: making a difference in the lives of young women in developing countries," Sexual and Relationship Therapy 15(3): 233-45.

World Health Organization. 2005. "WHO multi-country study on women's health and domestic violence against women: Summary report of initial results on prevalence, health outcomes and women's responses." Geneva: World Health Organization. 


\section{Hgrizons}

Horizons is a global operations research program designed to:

- Identify and test potential strategies to improve HIV/AIDS prevention, care, and support programs and service delivery.

- Disseminate best practices and utilize findings with a view toward scaling up successful interventions.

\section{(P) Population Council}

Horizons is implemented by the Population Council in collaboration with

- International Center for Research on Women (ICRW)

- International HIV/AIDS Alliance

- PATH

- Tulane University

- Family Health International (FHI)

- Johns Hopkins University

For more information, please contact:

Horizons Program, Communications Unit 4301 Connecticut Avenue, NW Suite 280 Washington, DC 20008 USA

Tel: 202-237-9400

Fax: 202-237-8410

Email: horizons@popcouncil.org www.popcouncil.org/horizons 